\title{
COVID-19, Mental Health and Cancer
}

\author{
Lindsay B. Carey ${ }^{1} \cdot$ Jeffery Cohen ${ }^{2,3} \cdot$ Harold G. Koenig ${ }^{4,5,6}$ - Ezra Gabbay ${ }^{7}$. \\ Jacinda R. Carey ${ }^{1} \cdot$ Carl Aiken $^{8,9}$
}

Accepted: 14 June 2021 / Published online: 21 June 2021

(C) The Author(s), under exclusive licence to Springer Science+Business Media, LLC, part of Springer Nature 2021

\section{Introduction}

The key themes addressed in this issue of JORH (2021) concern three formidable global issues that are challenging all nations, namely (i) COVID-19, (ii) mental health, and (iii) cancer (JORH, 2021). All three issues necessitate considerable research, resourcing, and responsive action to hopefully avoid calamities for both present and future generations.

Lindsay B. Carey

Lindsay.Carey@1atrobe.edu.au

Jeffery Cohen

Jeffrey.Cohen@nd.edu.au

Harold G. Koenig

Harold.Koenig@duke.edu

Jacinda R. Carey

Jacinda.Carey@latrobe.edu.au

Carl Aiken

CAiken@drew.edu

1 Public Health Palliative Care Unit, La Trobe University, Melbourne, Australia

2 School of Medicine (Sydney), University of Notre Dame Australia, Sydney, NSW, Australia

3 St Vincent's Private Hospital Sydney, Darlinghurst, NSW, Australia

4 Department of Psychiatry and Behavioral Sciences, Duke University Health Systems, Durham, NC, USA

5 Department of Medicine, Duke University Health Systems, Durham, NC, USA

6 Department of Medicine, King Abdulaziz University, Jeddah, Saudi Arabia

7 Division of General Internal Medicine, Department of Medicine, Hospital Medicine Section, Weill Cornell Medicine, New York, NY, USA

8 Drew University Alumni, Maddison, NJ, USA

9 Royal Women's and Children's Hospital, Adelaide, South Australia, Australia 


\section{COVID-19}

This is now the sixth issue of JORH that has presented research and professional commentary featuring COVID-19. Since the last editorial (Carey et al., 2021), this pandemic continues to burgeon and significantly impact society despite a variety of vaccination efforts, with cases now rising (at the time of writing) towards 180 million and 4 million deaths worldwide (WHO, 2021). The majority of these are currently occurring within the USA; however, India's increased transmissions look to out-pace all countries. This is due to India's public health resource constraints including a critical shortage of COVID-19 vaccines (Cunningham et al., 2021). Indeed, COVID-19 cases in India, if not brought under control, will soon surpass tuberculosis (TB) as the leading infectious disease in India (which accounts for the highest percentage of TB cases in the world: i.e., 26\%). Indeed, TB in India is actually increasing because COVID-19 is hampering TB eradication programs (WHO, 2020a). This is a secondary and very sad consequence of the current pandemic.

To support research and commentary relating to COVID-19, JORH will have published (by August 2021) 58 articles from numerous countries, which according to SCOPUS forms approximately $9 \%(n=58 / 637: 9.1 \%)$ of all articles published on 'COVID-19 and Religion or Spirituality'. This number, however, is a very small drop in the ocean compared to the total number of articles now published globally on COVID-19 within peer-reviewed refereed journals; articles which exceed over 150,00 in approximately only 2 years (see Table 1 ).

Within this issue, JORH considers (i) the link between COVID-19, anxiety, and religious beliefs in the United States and the United kingdom, (ii) spiritual support during COVID-19 in England, (iii) the impact of COVID-19 and religious restrictions on the well-being of Ghanaian Christians, (iv) the relationship between COVID-19, euthanasia and old age, (v) principles of Dungaw in relation to COVID-19, (vi) how resiliency and hope can predict the stress of COVID-19, (vii) the historical lessons of Saint Roch and social distancing during pandemics, (viii) how Roman Catholic liturgy can respond to the COVID-19 pandemic, (ix) the importance of congregational COVID-19 conversations through the utilization of medical-religious partnerships, (x) the 'just-in-time' COVID-19 training in Catholic schools, (xi) meaning in life, religious coping, and loneliness during the COVID-19 health crisis in Turkey, (xii) the role of Islamic clerics in accepting or contesting the COVID-19 crisis in Iran, (xiii) an examination of the role of (non)religiousness/ (non)spirituality in coping with COVID-19, and finally (xiv) the discrepancies and

Table 1 COVID-19 refereed journal articles published 2019-2021 (June)

\begin{tabular}{lll}
\hline Year & Articles published & Cumulative \\
\hline 2019 & 54 & 54 \\
2020 & 84,731 & 84,785 \\
2021 & $68,663^{* *}$ & 153,448 \\
\hline
\end{tabular}

Source: SCOPUS/Elsevier (2021): 'COVID-19 and Religion/Spirituality'

**Total June 2021, Figures do not include non-peer reviewed refereed publications 
similarities in attitudes, beliefs, and familiarity with vaccinations between religious students and science students in Malaysia.

\section{Mental Health}

The global social analysts, Goldin and Muggah (2020), note that mental health disorders are among the largest contributors to global mortality and morbidity, and that one in four persons will experience a mental disorder during their life (p. 367). Following on from a previous issue of JORH noting the significance of mental health (Carey, 2020; JORH, 2020), this issue considers the serious effects of mental health both positive and negative by exploring (i) the association between religious belief and treatment adherence, among those with mental illnesses, (ii) the effect of spirituality on the subjective recovery of psychiatric patients, (iii) mental health and religiosity in the Sardinian Blue Zone, (iv) the core cultural formulation interview in yielding religious content among patients suffering from a current major depressive episode, (v) investigation of the spiritual care effects upon anxiety, depression, psychological distress and spiritual levels of Turkish Muslim radiotherapy patients, (vi) and a large-scale international and individual analysis considering the effects of different religious beliefs upon mental health.

Other topics that relate to mental health include, (vii) suicide across Buddhism, American Indian-Alaskan natives, plus African traditional religions, atheism and agnosticism, (viii) spirituality and suicidality among patients with schizophrenia in Nigeria, (ix) effects of church attendance versus private religious activities on suicidal ideation among rural US college students, (x) religious struggles, psychological distress and the mediating role of psychosocial resources, (xi) a systematic review and meta-analysis of relationships between religiosity and constructive or destructive behaviors of employees, (xii) conflicting advice by spiritual leaders, friends, family, and mental health providers, (xiii) intrapsychic conflicts arising while meeting Ultraorthodox patients, (xiv) investigating the effect of religious and Islamic teachings on calmness and mental health in educational spaces, (xv) associations between religious/spiritual coping and depression among adults with cystic fibrosis, (xvi) adolescent gender and age differences in religiously and spiritually-motivated types of forgiveness and the relationship to depressive symptoms, (xvii) resilience in the aftermath of childhood abuse, (xviii) contending with spiritual reductionism: demons, shame, and dividualising experiences among evangelical Christians with mental distress, (xix) and finally posttraumatic growth based on Professor Beth Rodgers' concept development.

\section{Cancer}

Cancer remains a persistent leading cause of death worldwide, accounting for nearly 10 million deaths in 2020 (WHO, 2020b). Koenig et al. (2012), note that "patients with cancer must deal with a life-threatening, frightening and sometimes disfiguring disease and must endure the symptoms of the cancer and the unpleasant side effects 
of treatment' (p. 108). Cancer is debilitating for all, irrespective of age, citizenship, religious/spiritual beliefs or social status and exerts 'tremendous physical, emotional and financial strain on individuals, families, communities and health systems' - a very costly disease for all societies (WHO, 2020c). It has already been argued in a previous issue of JORH (2020), 'that the two main inhibitors regarding the prevention and treatment of cancer are lack of government commitment and inadequate research funding. If only nations would enthusiastically seek a solution for cancer as earnestly as a vaccine for COVID-19' (Carey, 2020, p. 2668)-then another life destroying and fiscally crippling disease, affecting people and subsequently all economies, would be eradicated.

The collation of articles in this issue of JORH considers, (i) the effect of religious belief on depression and hopelessness in advanced cancer patients, (ii) the effect of religious coping on hope in cancer patients receiving chemotherapy, (iii) the relationship between spirituality and hope ("hope to see the soul"), (iv) complementary, traditional and spiritual practices used by cancer patients in Turkey when coping with pain, (v) psychological hardiness and spirituality in patients with primary brain tumours in Turkey, (vi) an exploration of suffering and spirituality among older African-American cancer patients as guided by Howard Thurman's theological perspective on spirituality.

Other submissions in this issue related to cancer examine (vii) spirituality, religiosity and coping strategies among Spanish people diagnosed with cancer, (viii) spiritual beliefs of Jordanian adult patients receiving palliative care, (ix) perspectives of spirituality and spiritual care among healthcare providers in a hospice setting in Pakistan ("I need presence and a listening ear"), (x) the opinions of Iranian parents regarding the power of religious beliefs and coping with cancer, (xi) the role of cognitive reappraisal and coping self-efficacy in mediating the link between religious coping and well-being, (xii) the motivations and experiences regarding spiritual care through the voices of spiritual care workers at a hospice in Cape Town, South Africa, (xiii) exploring how nursing students in Turkey understand the concept of cancer based on exploratory metaphor analysis, (xiv) a systematic review of spirituality-integrated interventions for caregivers of patients with terminal illness, and finally (xv) religious meaning and resilience in spouse caregivers of cancer patients.

\section{Upcoming Issues}

Again, as noted in the previous editorial, the topic of moral injury (affecting military, civilian, and health care professionals) has been gaining increasing recognition particularly from a religious/spiritual perspective (Carey \& Hodgson, 2018). Submissions to JORH continue to be welcomed on this topic. Further, this year marks two decades since that devastating event of September 11th 2001. Even at this late stage, authors are encouraged to consider reflecting upon September 11th. Please feel free to contact one of the editors if you wish to submit a paper about either of these topics. Submissions are made through the Editorial Manager on the JORH web site: https://www.springer.com/journal/10943/submission-guidelines. 


\section{References}

Carey, L. B., Cohen, J., Koenig, H. G., Gabbay, E., \& Carey, J. R. (2021). COVID-19, Sex, addictions, women's health, care of the elderly, and medical education. Journal of Religion and Health, 60(3), 1425-1429. https://doi.org/10.1007/s10943-021-01264-z

Carey, L. B. (2020). COVID-19, aged care, cancer, medical research and mental health. Journal of Religion and Health, 59(6), 2667-2670. https://doi.org/10.1007/s10943-020-01127-z

Carey, L. B., \& Hodgson, T. J. (2018). Chaplaincy, spiritual care and moral injury: Considerations regarding screening and treatment. Frontiers in Psychiatry, 9(619), 1-10. https://doi.org/10.3389/ fpsyt.2018.00619

Cunningham, E., Shammas, B., Kornfield M. (2021, May 4). India's vaccine shortage to last months, top manufacturer warns. The Washington Post. USA: Washington, DC. https://www.washingtonpost. com/nation/2021/05/03/coronavirus-covid-live-updates-us/.

Goldin, I., \& Muggah, R. (2020). Terra incognita: 100 maps to survive the next 100 years. London: Penguin. https://www.penguin.com.au/books/terra-incognita-9781529124194.

JORH. (2021). Journal of Religion and Health, 60(4). New York: Springer Nature. https://link.springer. com/journal/10943/volumes-and-issues/60-4.

JORH. (2020). Journal of Religion and Health, 59(6). New York: Springer Nature. https://link.springer. com/journal/10943/volumes-and-issues/59-6.

Koenig, H., King, D.A., Carson, V.B. (2012). Handbook of Religion and Health (2 ${ }^{\text {nd }}$ ed.). Oxford University Press.

SCOPUS (2021). SCOPUS Data Base. Netherlands: Elsevier https://www.elsevier.com/solutions/scopus.

WHO (2020a). The COVID-19 pandemic and TB: Impact and implications. In: WHO. Global Tuberculosis Report 2020. (pp. 15 - 19). Geneva: World Health Organization.

WHO (2020b). International agency for research on cancer. Geneva: World Health Organization. https:// gco.iarc.fr/today/fact-sheets-cancers.

WHO (2020c). Cancer. Geneva: World Health Organization. https://www.who.int/health-topics/cancer.

WHO (2021). WHO-COVID-19-Statistics. Geneva: World Health Organization. https://covid19.who.int/.

Publisher's Note Springer Nature remains neutral with regard to jurisdictional claims in published maps and institutional affiliations. 